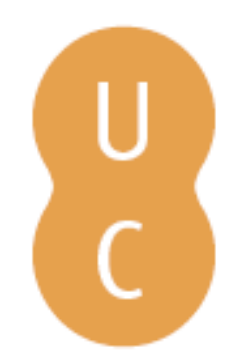

\title{
pommalina
}

\section{Pasteur visto por Miguel Bombarda}

\author{
Autor(es): Namorado, Sérgio \\ Publicado por: Imprensa da Universidade de Coimbra \\ URL \\ persistente: URI:http://hdl.handle.net/10316.2/32346 \\ DOI: $\quad$ DOI:http://dx.doi.org/10.14195/978-989-26-0362-9_21
}

Accessed : $\quad$ 26-Apr-2023 09:27:27

A navegação consulta e descarregamento dos títulos inseridos nas Bibliotecas Digitais UC Digitalis, UC Pombalina e UC Impactum, pressupõem a aceitação plena e sem reservas dos Termos e Condições de Uso destas Bibliotecas Digitais, disponíveis em https://digitalis.uc.pt/pt-pt/termos.

Conforme exposto nos referidos Termos e Condições de Uso, o descarregamento de títulos de acesso restrito requer uma licença válida de autorização devendo o utilizador aceder ao(s) documento(s) a partir de um endereço de IP da instituição detentora da supramencionada licença.

Ao utilizador é apenas permitido o descarregamento para uso pessoal, pelo que o emprego do(s) título(s) descarregado(s) para outro fim, designadamente comercial, carece de autorização do respetivo autor ou editor da obra.

Na medida em que todas as obras da UC Digitalis se encontram protegidas pelo Código do Direito de Autor e Direitos Conexos e demais legislação aplicável, toda a cópia, parcial ou total, deste documento, nos casos em que é legalmente admitida, deverá conter ou fazer-se acompanhar por este aviso.

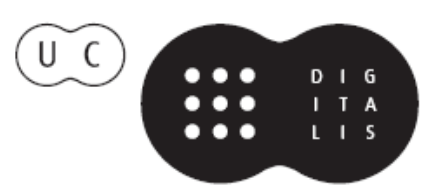


Ana Leonar Pereira Jםão Rui Pita [ Coordenaçä̃ ]

\section{Miguel Bomberda e as singularidades de uma época}

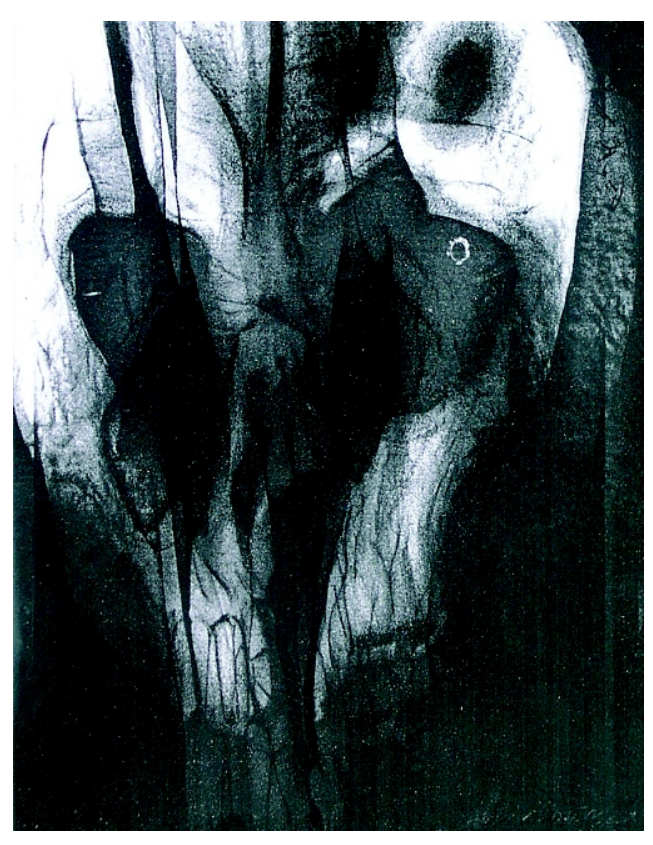


(Página deixada propositadamente em branco) 
Ana Leonor Pereira

João Rui Pita

(Coordenação)

\title{
FOLHA DE ROSTO
}

\author{
Miguel Bombarda (1851-1910)
}

a as singularidades de uma época 


\section{Coordenação Científica da Colecção Ciências e Culturas}

João Rui Pita e Ana Leonor Pereira

Os originais enviados são sujeitos a apreciação científica por referees

\section{Coordenação Editorial}

Maria João Padez Ferreira de Castro

\section{Edição}

Imprensa da Universidade de Coimbra

Email: impresauc@ci.uc.pt

URL: http://www.imp.uc.pt • Normas de publicação de colecções

Design

António Barros

Pré-Impressão

António Resende

Imprensa da Universidade de Coimbra

Capa

António Dantas. Sem título, 2002. Col. António Barros. Coimbra

Impressão e Acabamento

SerSilito • Maia

\section{ISBN}

978-989-8074-11-9

\section{Depósito Legal}

Obra publicada com a colaboração de:
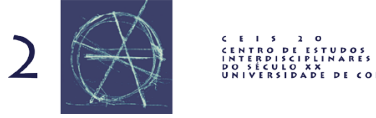

Obra publicada com o apoio de:

FCT Fundação para a Ciência e a Tecnologia

MINISTÉRIO DA CIÊNCIA, TECNOLOGIA E ENSINO SUPERIOR Portugal

Programa Operacional Ciência, Tecnologia, Inovação do Quadro Comunitário de Apoio III

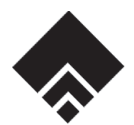

Fundaçāo Eng. António de Almeida

(C) Agosto 2006, Imprensa da Universidade de Coimbra 


\section{Sérgio Namorado}

Pós-Graduado em Ciências Documentais;

Mestrando, Faculdade de Letras da Universidade de Coimbra, Portugal

\section{Pasteur Visto por Miguel Bombarda}

Miguel Bombarda manteve-se sempre atento aos novos ventos da ciência que sopravam por toda a Europa de então. À frente de toda essa corrente de inovação, encontrava-se a personalidade de Louis Pasteur, a mais importante figura da ciência da sua época.

\section{Pasteur: A ciência ao serviço de uma Medicina inteiramente nova}

Segundo a imagem do químico francês traçada por Miguel Bombarda, Pasteur, sem ser médico, contribuiu para o evoluir da Medicina muito mais do que qualquer especialista terá feito. Novas esperanças floresceram, mais saber se produziu.

As experiências efectuadas por muitos dos seus contemporâneos, nomeadamente Koch, mais não foram do que novos tijolos acrescentados ao já de si imenso edifício da obra pasteuriana. Na cúpula deste edifício, encontra-se a consagração máxima de toda uma vida: a vacina contra a raiva. A raiva era uma doença rebelde e temível para os povos de todo o mundo e à volta da qual se havia construído um mito de invencibilidade.

O facto de Pasteur ter encontrado a cura da raiva fez surgir a ideia de que nenhuma doença seria invencível para sempre, por mais difícil de combater que fosse. Surgia uma nova atitude e entrava-se assim numa nova etapa no combate às mais perigosas moléstias.

\section{Pasteur: A perseverança genial}

O seu rigor matemático, associado a uma perseverança única e a uma curiosidade permanentemente insatisfeita, levaram-no a conseguir resultados que mais nenhum cientista do seu tempo alguma vez teria sonhado.

Obedecendo a um método de trabalho amadurecido ao longo de anos onde a experimentação era levada, sempre que possível até às últimas consequências, Pasteur conseguia ser absolutamente preciso e ao mesmo tempo modesto na apresentação dos seus resultados. Nada era definitivo e cada descoberta não era mais do que uma 
etapa, fecunda em novas hipóteses. Estas eram confirmadas ou refutadas mediante novas experiências.

Pasteur não declarava vitória, limitava-se a apresentar resultados, sempre comprovados no mais pequeno detalhe. Anos a fio de trabalho intenso, levaram-no a desenvolver um espírito regido por uma lógica de rigor científico, confiante, optimista e persistente. Os factos reais observados e os sucessos progressivos de Pasteur no vencer de novas etapas da sua caminhada científica, vieram confirmar a fecundidade do seu método e da sua lógica de pesquisa.

As investigações que havia efectuado no campo das fermentações, aparentemente tão limitadas na sua utilidade, deram-lhe as bases fundamentais para, mais tarde, poder compreender com mais precisão os fenómenos biológicos.

Deste modo, Pasteur conseguiu grandes progressos e resultados no campo da microbiologia, área do saber que, então, dava os primeiros passos, que foram também os mais importantes.

Louis Pasteur surge, para Miguel Bombarda, como o exemplo máximo de homem de ciência, profundamente dedicado ao seu trabalho empreendedor e ambicioso nos seus objectivos, mas profundamente modesto e pouco exuberante no contacto pessoal.

Admirava ainda a sua relativa indiferença às demonstraçôes de júbilo popular de que foi alvo no fim da vida, embora as recebesse com a mais profunda gratidão.

Pasteur era, para Miguel Bombarda um modelo perfeito de ser humano.

\section{BIBLIOGRAFIA}

"Academia real das sciencias" (Pasteur nomeado sócio da Academia) in "Sociedades scientificas», A Medicina Contemporanea, Lisboa, ano 4, no 15, 11 de Abril de 1886, p. 125.

Aguiar, Alberto d' - «Influencia da chimica em medicina», Porto Medico, Porto, ano 2, no 11, Novembro de 1905 , pp. 349-375.

— «Influencia da chimica em medicina». Cit. por F. S. in "Bibliografia», Revista de Chimica Pura e Applicada, Porto, ano 2, 1906, pp. 71-72.

Boléu, Luísa Paiva - "Como um santo laico», Público Magazine, no 289, 24 de Setembro de 1995, (Suplemento de Domingo do jornal) Público, Porto, ano 6, no 2025, 24 de Setembro de 1995, pp. 48-55.

Bombarda, Miguel - «Hospitalização dos tuberculosos» (Cit.) in «Sociedade das Sciencias Medicas de Lisboa» in "Trabalhos das sociedades scientificas portuguesas", Revista Portugueza de Medicina e Cirurgia Praticas, Lisboa, ano 2, no 29, 1 de Janeiro de 1898, pp. 157-158.

BombardA, Miguel - «Pasteur» (Breve mas aprofundado, estudo sobre Louis Pasteur e a sua importância na história da Medicina), A Medicina Contemporanea, Lisboa, ano 13, no 40, 6 de Outubro de 1895 , pp. 314-323.

Bombarda, Miguel - «Pasteur». Publicação da «Medicina Contemporanea», Lisboa, Livraria Rodrigues, $1895,30 \mathrm{pp}$.

BOMBARDA, Miguel - «A vaccina da raiva (Extracto do relatorio apresentado ao conselho da Escola medicocirúrgica de Lisboa, pelo prof. M. B.) in 'Trabalhos originaes'», A Medicina Contemporanea, Lisboa, ano 5, no 14, 3 de Abril de 1887, pp. 105-108; no 15, 10 de Abril de 1887, pp. 113-116; no 17, 24 de Abril de 1887, pp. 129-132.

BOMBARDA, Miguel (?) - Editorial sem autor expresso, datado de 12 de Julho de 1884 ( Cólera e higiene), A Medicina Contemporanea, Lisboa, ano 2, no 28, 13 de Julho de 1884, p. 217. 
Bombarda, Miguel - Idem, datado de 26 de Julho de 1884 (Cólera e higiene), A Medicina Contemporanea, Lisboa, ano 2, no 30, 27 de Julho de 1884, pp. 233-234.

Bombarda, Miguel - Idem, datado de 2 de Agosto de 1884 (Cólera e profilaxia), A Medicina Contemporanea, Lisboa, ano 2, no 31, 3 de Agosto de 1884, pp. 241-243.

BOMBARDA, Miguel - Idem, onde se refere o dia 26 de Outubro de 1885, em que se iniciou um a nova etapa para a Medicina: a apresentação da descoberta da vacina contra a raiva, por Louis Pasteur, $A$ Medicina Contemporanea, Lisboa, ano 3, no 45, 8 de Novembro de 1885, p. 357.

Bombarda, Miguel - Idem, datado de 2 de Janeiro de 1886 (Progressos da Medicina e higiene), A Medicina Contemporanea, Lisboa, ano 4, $\mathrm{n}^{\circ}$ 1, 3 de Janeiro de 1886, pp. 1-2.

Bombarda, Miguel - Idem, datado de 10 de Abril de 1886 (Sobre o médico enviado a Paris, para estudar o novo método de Pasteur contra a raiva) (Excerto), A Medicina Contemporanea, Lisboa, ano 4, no 15 , 11 de Abril de 1886, p. 121.

Bombarda, Miguel «Um precursor de Pasteur» (Hameau) in "Curiosidades Medicas», A Medicina Contemporanea, Lisboa, ano 17, no 17, 16 de Abril de 1899, pp. 130-131.

— «Novos trabalhos sobre a raiva» (Comunicação de Pasteur) in "Movimento scientifico", A Medicina Contemporanea, Lisboa, ano 2, no 12, 23 de Março de 1884, p. 95.

SANTOS, João Marques dos - A vida e obra de Louis Pasteur. Sua influência na Universidade de Coimbra e na Cidade de Coimbra. Conferência..., Coimbra, Imprensa da Universidade de Coimbra, 1923, 1 fl., 154/96, 65 pp.

SiLvA, Agostinho da - Vida de Pasteur, Col. Obras de Agostinho da Silva. Edição de José A. Ribeiro. Lisboa, Ulmeiro - Livraria e Distribuidora Lda, 1989, 98 pp.

TORGO (JUNIOR), Alves - «Vaccinação carbunculosa» e "Manual operatorio de vaccinação", in "Secção de Medicina Veterinaria", Revista de Medicina Dosimetrica, Porto, ano 3, nº 24, Abril de 1882, pp. $482-484$.

— «Tratamento pasteureano de prophylaxia antirabica» in «Miscellanea», Coimbra Medica, Coimbra, ano 7, no 20, 15 de Outubro de 1887, p. 308.

— «A vaccina da raiva» in «Variedades», A Medicina Contemporanea, Lisboa, ano 5, no 41, 9 de Outubro de 1887 , p. 326.

Zweig-Winternitz, F. M. - Pasteur - O Sábio e o Grande Amigo da Humanidade. Tradução de Maria Henriques Osswald F. I. L. Porto, Livraria Civilização - Editora, 1940, 232 pp.

Resumo - Miguel Bombarda manteve-se atento aos novos ventos da ciência que sopravam por toda a Europa de então. À frente de toda essa corrente de inovação encontrava-se a personalidade de Louis Pasteur, a mais importante figura da ciência da sua época. No presente poster dá-se a conhecer o modo como Miguel Bombarda analisou a figura de Pasteur.

Abstract - Miguel Bombarda was aware of the new winds of science that blew all over Europe during his time. Heading this innovation movement was Louis Pasteur, the most important figure of science at the time. The poster aims at showing the way Miguel Bombarda analysed the figure of Pasteur. 


\section{Colecção \\ Ciências e Culturas \\ Cuimbra 2006}

